\title{
Confrontation and Dissection on E-Retailing Sales Chart Using Process Mining Tools
}

\author{
B Devipriya \\ Research Scholar \\ VISTAS, Chennai \\ jivipriya12@gmail.com
}

\author{
Dr.Y.Kalpana \\ Professor \\ Department of BCA \& IT \\ VISTAS, Chennai \\ ykalpanaravi@gmail.com
}

\begin{abstract}
The electronic retailing (e-Tailing, e-Retailing, web retailing and so on.) is the model of offering of retail products utilizing electronic media, specifically, the web. E-Retailing is a subset of web based business (Electronic Commerce). The business-to-customer part of electronic trade (online business) is the most unmistakable business utilization of the World Wide Web. The essential objective of an e-commerce site is to offer merchandise and enterprises on the web. This paper has made an endeavor to locate the best and reasonable apparatuses for mining the procedure in view of the prerequisites and it is move in deals outline of online item class as illustration.
\end{abstract}

Key Words: E-Retailing, Process Mining Tool, Frame Work.

\section{INTRODUCTION}

Process Mining is to naturally decide and break down real process execution-How the procedures are performing in an entire new and process arranged way. The fundamental thought of Process Mining is to separate Knowledge from occasion logs. An Event log contains Historical information of genuine process execution. Process Mining used to store information in various Process Management Systems, and it can be used for a superior future reference of the real procedure[1]. Process Mining is a scaffold between information mining and business process administration and the objective is to remove data from the Event logs more often than not contain information about cases (i.e Process Instance) that have been executed in the Organization[2].

Vol 1 (10), April 2018, www.ijirase.com

\section{E-RETAILING PROCESS MODEL}

Basics of E-Retailing:- There are sure basic parts for an e-Retailing business to be fruitful. Before setting up an electronic customer facing facade, one must consider these parts well ahead of time[3]. The vital fundamentals of e-Retailing are as:

- E-Catalog Products - stores products master data

- Search Engine Shopping Cart Suppliers stores suppliers master data Shippers stores shippers master data

- Distribution of Digital Goods

- Online Customer sales person

- Customers - stores customer master data Orders - stores transaction sale orders from customers

- Order Details - stores line items of sale orders

- An order status Checking Facility

- Create Consumer Community 
ISSN(Online) : 2456-8910

International Journal of Innovative Research in Applied Sciences and Engineering (IJIRASE)

Volume 1, Issue 10, DOI: 10.29027/IJIRASE.v1.i10.2018.193-196, April 2018

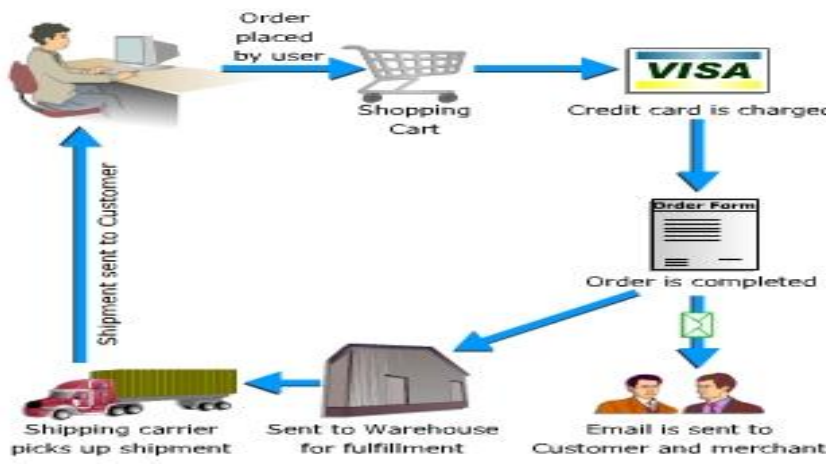

\section{PROCESS MINING-FRAME WORK}

Process mining focuses on the programmed disclosure of data from an occasion log. The found data can be utilized to send new frameworks that help the execution of business forms or as a criticism instrument that aides in reviewing, dissecting and enhancing as of now ordered business forms. The primary advantage of process mining procedures is that data is dispassionately aggregated[4][5]. As such, process mining procedures are useful in light of the fact that they accumulate data about what is really occurring as per an occasion log of an association, and not what individuals imagine that is going on in the association[6].

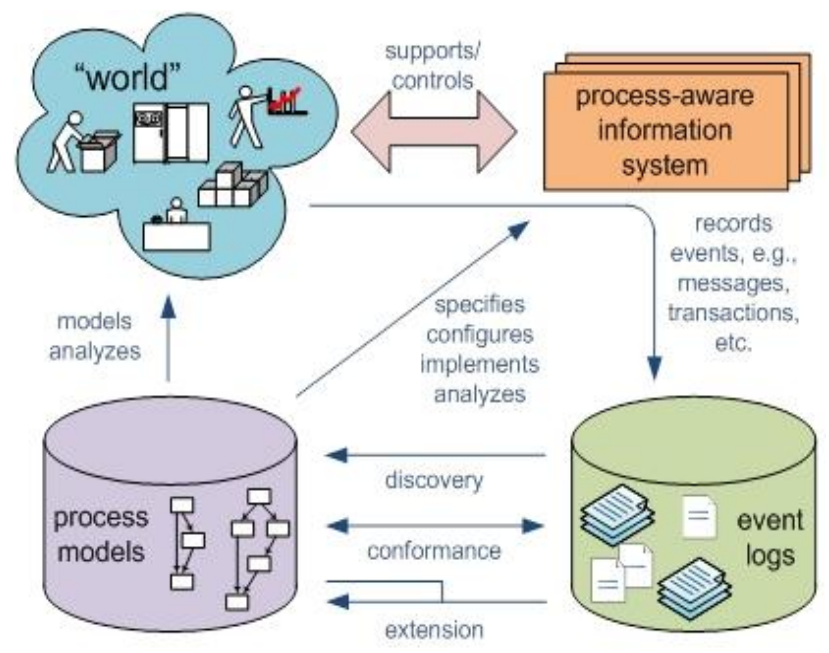

Vol 1 (10), April 2018, www.ijirase.com

\section{CLASSIFICATION OF INPUTS AND OUTPUTS}

\section{4a.ProM}

Prom is open-source structure for actualizing process mining instruments in a standard situation. Prom is utilized for mining controlspill out of occasion $\operatorname{logs}$ [7]. The log give the errand that are executed all the while and construe their request of execution and connection these assignments to singular cases, at that point the control-stream viewpoint can be mined[8]. The system can likewise tell which modules fit with given an arrangement of information composes and a given arrangement of yield writes. Assume we have an occasion log, and we need to make a Petri net model from this log. At that point we can essentially choose the "Occasion log" type as contribution for the module and the "Petri net" sort not surprisingly yield, and the activity view will demonstrate to us the rundown of modules that really take an occasion log as info and deliver a Petri net as yield[9].[10].

\section{4b.Disco}

Disco stands for discovery, and disco is on the market now since 2012[11].The program really a great academic tool set, which makes it very easy for researchers to develop new algorithms, for example, Disco's really meant for business professional, who does not need to know anything about how these algorithms work, and how the technology looks like under the hood[12].

Disco additionally includes an alternate route import and information trade for beforehand foreign informational indexes with up to 200xspeed-up for expansive informational collections through the local FXL Disco log record organize. Disco utilizes an 
ISSN(Online) : 2456-8910

International Journal of Innovative Research in Applied Sciences and Engineering (IJIRASE)

Volume 1, Issue 10, DOI: 10.29027/IJIRASE.v1.i10.2018.193-196, April 2018

instinctively justifiable and 100\% honest process delineate[13]. The thickness of ways and shading of exercises demonstrate the fundamental ways of the procedure streams, and inefficient improve circles like in the acquiring illustration process beneath are immediately found[14].

\section{CLASSIFICATION OF FUNCTIONS}

It indicate the utilization of Process digging Techniques and apparatuses for an assortment of issues and related capacities (or activities) used to confirm the procedure[15].

1. Inspecting and Cleaning occasion information is made by Filtering the information before removed occasion $\log$ is utilized

2. Understanding the Business Process should be possible by Process Discovery-in view of an occasion log, some demonstrate is Constructed, Conformance Checking-method bolsters the model change and cases digress from the model and redress are required are concentrated, Social Network Mining-given a log with asset data used to find the connections between assets, Decision Rule Mining-Machine Learning Algorithm are applied on top of business process model, Process Visualization-animate past process animation.

3. Performance Issues includes performance reporting such as calculating Waiting and service times, cycle time analysis, flow time analysis and bottleneck detection.

\begin{tabular}{|c|c|c|c|c|c|c|}
\hline$M C$ & -Comn & irce Pu & $\begin{array}{l}\text { chase Cat } \\
\text { internet users aged } \\
\text { ugust } 2016\end{array}$ & $\begin{array}{l}\text { gories, } \\
64 \text { in each co }\end{array}$ & by Country & \\
\hline Market & Category 1 & $\stackrel{\%}{\%}$ purchasing & Category 2 & $\begin{array}{c}\% \\
\text { purchasing }\end{array}$ & Category 3 & $\begin{array}{l}\% \% \\
\text { purchasing }\end{array}$ \\
\hline United States & Fashion & $88 \%$ & Technology & $87 \%$ & Culture & $86 \%$ \\
\hline England & Culture $^{*}$ & $92 \%$ & Fashion & $89 \%$ & Technology & $88 \%$ \\
\hline France & Fashion & $87 \%$ & Culture & $86 \%$ & Technology & $81 \%$ \\
\hline Belgium & Fashion & $80 \%$ & Leisure travel & $77 \%$ & Culture & $75 \%$ \\
\hline Germany & Fashion & $90 \%$ & Culture & $90 \%$ & Household items & $88 \%$ \\
\hline Netherlands & Fashion & $87 \%$ & Culture & $80 \%$ & Leisure travel/HH items & $80 \%$ \\
\hline Denmark & Technology & $85 \%$ & Leisure travel & $84 \%$ & Culture & $83 \%$ \\
\hline Sweden & Technology & $87 \%$ & Culture & $86 \%$ & Fashion & $86 \%$ \\
\hline Spain & Technology & $87 \%$ & Leisure travel & $86 \%$ & Fashion & $82 \%$ \\
\hline Italy & Technology & $89 \%$ & Culture & $82 \%$ & Fashion & $80 \%$ \\
\hline China & Food & $94 \%$ & Fashion & $92 \%$ & Household items & $89 \%$ \\
\hline Hong Kong & Fashion & $87 \%$ & Leisure travel & $79 \%$ & Technology & $74 \%$ \\
\hline Singapore & Fashion & $85 \%$ & Leisure travel & $79 \%$ & Health-beauty & $76 \%$ \\
\hline Australia & Fashion & $82 \%$ & Culture & $82 \%$ & Technology & $82 \%$ \\
\hline India & Fashion & $93 \%$ & Household items & $90 \%$ & Technology & $89 \%$ \\
\hline
\end{tabular}

\section{6b.PromLite1.2}

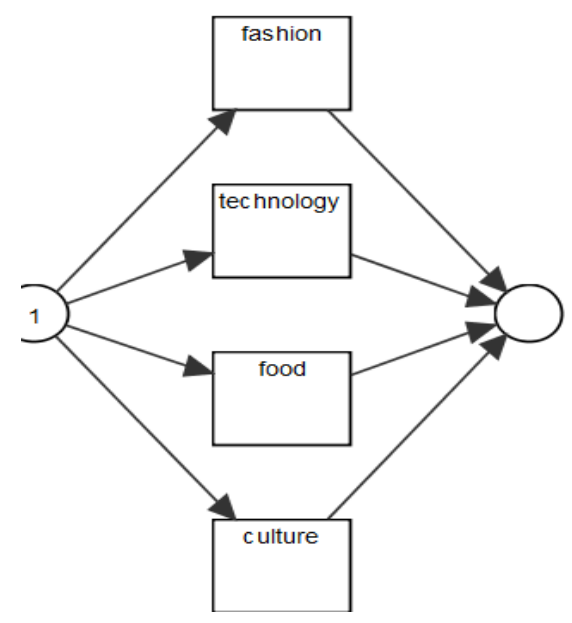

6c.Disco 2.1.0

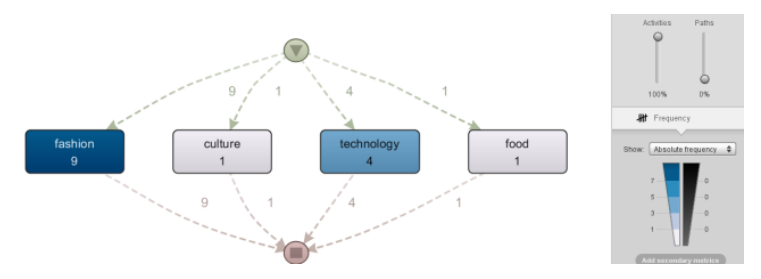

\section{VII.SUMMARY}

\begin{tabular}{|l|l|l|}
\hline Features & ProM & Disco \\
\hline Product & ProM Lite & Disco \\
\hline
\end{tabular}

\section{VI.PROCESS MINING TOOLS 6a.Example Chart}




\begin{tabular}{|l|l|l|}
\hline Name & 1.2 & 2.1 .0 \\
\hline $\begin{array}{l}\text { Product } \\
\text { Version }\end{array}$ & Application & Application \\
\hline Type & Mxml, xes xls, & $\begin{array}{l}\text { Csv, } \\
\text { mxml, xes }\end{array}$ \\
\hline Input Type & $\begin{array}{l}\text { BPMN, WF, } \\
\text { Petrinets, EPCs }\end{array}$ & Fuzzy Model \\
\hline Output Type tool & $\begin{array}{l}\text { This Contain } \\
\text { six powerful }\end{array}$ \\
\hline $\begin{array}{l}\text { Supported } \\
\text { features } \\
\text { This pontains a wide } \\
\text { variety of plug- } \\
\text { ins }\end{array}$ & Filter. \\
\hline $\begin{array}{l}\text { Supported } \\
\text { Platform } \\
\text { desktop version }\end{array}$ & $\begin{array}{l}\text { Standalone } \\
\text { desktop } \\
\text { version }\end{array}$ \\
\hline $\begin{array}{l}\text { Importance } \\
\text { of design } \\
\text { priorities }\end{array}$ & $\begin{array}{l}\text { Discovery, } \\
\text { Conformance, } \\
\text { Extension }\end{array}$ & $\begin{array}{l}\text { Usability, } \\
\text { Fidelity, } \\
\text { Performance }\end{array}$ \\
\hline
\end{tabular}

\section{VIII.CONCLUSION}

The created system select and center for the most part around the activities that utilization procedure mining apparatus. Since, our concentration was to approach the similar investigation based on the upheld/unsupported tasks.

Notwithstanding the absence of inside and out investigation on a genuine log, the structure can be utilized to comprehend process mining devices from an alternate point of view not at all like comparable works. It is difficult to sum up the aftereffects of process and breaking down the devices utilizing lacking in accessibility of information so the translation of the discoveries may be influenced. At long last, the finishes of the correlation may be unique if the assessment has been performed by master clients of the individual apparatuses or by the device sellers themselves.

\section{IX.REFERENCES}

1. Dr.P.V.Kumaraguru, Dr. S.P. Rajagopalan, "Process Modelling from Insurance Event Log “ International Journal of Computer Applications (0975 - 8887) volume38 .

2. P.V.Kumaraguru, Dr.S.P.Rajagopalan ,' Model discovery from Motor claim process using Process Mining Techniques", International Journal of Scientific and Research Publications, Volume 3,Issue 1, ISSN 2250-3153.

3. Dr.P.V. Kumaraguru, Dr. S.P. Rajagopalan, "Process Modelling from Insurance Event Log "International Journal of Computer Applications (0975 - 8887) volume 57.

4. https://fluxicon.com/disco

5. www.promtools.org/doku.php?id=tutorial:i ntroduction

6. www.marketingcharts.com, "Top-3 ecommerce purchase category" on 22 August 2016.

7. www.elsevier.com/locate/jretail,"JOURNA L OF RETAILING", ISSN: 0022-4359.

8. DR.S.Pugalanthi, "Retail Market In India", ISSN 2277.

9. Musie Kebede ,"Comparative Evaluation of Process Mining Tools “.

10. https://www.coursera.org/learn/processmining/lecture/mdGz0/introducingfluxicon-disco.

11. http://slideplayer.com/slide/4832546.

12. www.elsevier.com/locate/jretai ,"Journal of Retailing”, ISSN: 0022-4359.

13. International Journal of Scientific and Research Publications, Volume 3, Issue 1, January 20131 ISSN 2250-3153 .

14. www.managementstudyguide.com

15. The Use of Machine Learning Algorithms in Recommender Systems: 